\title{
Enhancing Lay Counselor Capacity to Improve Patient Outcomes with Multimedia Technology
}

\author{
Reuben N. Robbins • Claude A. Mellins • Cheng-Shiun Leu • \\ Jessica Rowe • Patricia Warne - Elaine J. Abrams • \\ Susan Witte · Dan J. Stein · Robert H. Remien
}

Published online: 8 January 2015

(c) Springer Science+Business Media New York 2015

\begin{abstract}
Multimedia technologies offer powerful tools to increase capacity of health workers to deliver standardized, effective, and engaging antiretroviral medication adherence counseling. Masivukeni-is an innovative multimediabased, computer-driven, lay counselor-delivered intervention designed to help people living with HIV in resourcelimited settings achieve optimal adherence. This pilot study examined medication adherence and key psychosocial outcomes among 55 non-adherent South African HIV+ patients, on antiretroviral therapy (ART) for at least 6 months, who were randomized to receive either Masivukeni or standard of care (SOC) counseling for ART nonadherence. At baseline, there were no significant differences between the SOC and Masivukeni groups on any outcome variables. At post-intervention (approximately
\end{abstract}

R. N. Robbins $(\bowtie) \cdot$ C. A. Mellins · C.-S. Leu $\cdot$ P. Warne

R. H. Remien

HIV Center for Clinical and Behavioral Studies, New York State Psychiatric Institute, Columbia University, 1051 Riverside Drive \#15, New York, NY 10032, USA

e-mail: rnr2110@columbia.edu

J. Rowe

The Columbia Center for New Media Teaching and Learning, Columbia University, New York, USA

\section{E. J. Abrams}

ICAP, Mailman School of Public Health and College of Physicians \& Surgeons, Columbia University, New York, NY, USA

\section{S. Witte}

Social Intervention Group, School of Social Work, Columbia University, New York, NY, USA

\section{J. Stein}

Department of Psychiatry and Mental Health, University of Cape Town, Cape Town, South Africa
5-6 weeks after baseline), -clinic-based pill count adherence data available for 20 participants (10 per intervention arm) showed a $10 \%$ improvement for-participants and a decrease of $8 \%$ for SOC participants. Masivukeni participants reported significantly more positive attitudes towards disclosure and medication social support, less social rejection, and better clinic-patient relationships than did SOC participants. Masivukeni shows promise to promote optimal adherence and provides preliminary evidence that multimedia, computer-based technology can help lay counselors offer better adherence counseling than standard approaches.

Keywords HIV - ART adherence - Technology · Multimedia $\cdot$ Task-shifting $\cdot$ Intervention

\section{Introduction}

With documented individual [1-3] and public health [4, 5] benefits of early antiretroviral therapy (ART), increasing numbers of people living with HIV worldwide are initiating treatment. However, optimal medication adherence is needed to achieve and sustain the viral suppression necessary for a person living with HIV to remain healthy and reduce the likelihood of transmitting the virus to others [68]. Unfortunately, achieving and sustaining high levels of medication adherence is a challenge for many individuals and requires ongoing attention as well as retention in care [9]. Over-burdened healthcare systems often must rely on minimally trained, non-clinical personnel (e.g., lay counselors) to implement behavioral interventions for adherence and provide ongoing support to patients living with HIV, some of which may be beyond the limits of their current competencies. This is especially true in high prevalence and resource-constrained settings such as Sub- 
Saharan Africa where some health service responsibilities have been shifted from physicians and nurses to less specialized personnel $[10,11]$ in the context of expanding ART programs [12-15].

In the Western Cape of South Africa, ART adherence counseling is performed by lay counselors who are usually trained and certified by non-governmental organizations (NGOs) that work with the national and local departments of health. These counselors typically receive about 1 month of adherence counseling training and, once certified, are placed in clinics to identify and address patients' adherence problems. However, support and supervision is often minimal and sporadic, and counseling can vary widely. In the face of this challenge, the use of technology has the potential to standardize and improve the quality of adherence intervention delivery.

Technology-based, multimedia interventions increasingly are being implemented to promote engagement, learning, standardization, and delivery of health interventions [16], and they have led to health improvements in asthma [17, 18], diabetes [19], smoking [20, 21], and alcohol use [22, 23] in the US. Compared to non-technology-based interventions, multimedia-based programs have demonstrated better short- and long-term efficacy for health behavior change and good feasibility across a range of populations [24-27]. Further, they are liked by users and appear to be more time efficient and cost-effective than traditional approaches $[28,29]$. Numerous computer-based HIV prevention interventions have been developed and have been shown to improve condom use [30]. One multimedia, patient-administered, computer-based intervention for ART adherence, "Life Windows," has been developed and tested in the US, which showed promise for software based programs to improve adherence behavior [31].

To address the antiretroviral adherence counseling needs of South Africa and the millions of HIV-infected individuals who are on or will be initiating ART, as well as the healthcare personnel shortage in that country, we developed a computer-based, multimedia adherence intervention for lay adherence counselor administration to patients on ART in South African health clinics. The computer-based component of the intervention serves as an interactive guide for the lay counselors to stay on track and ensure all the curriculum is delivered, and as an interactive tool to engage patients in their care, as well as in understanding HIV and ART. Working closely with South African and new media colleagues, we developed a 6-session, computer-based, multimedia adherence intervention designed to improve the quality and enhance the capacity of lay counselors to deliver Department of Health required ART adherence counseling. The intervention was adapted from the Sharing Medical Adherence Responsibilities Together (SMART) Couples intervention [32, 33], as well as from activities developed in Multimedia Connect [34]. The intervention was named "Masivukeni" ("Let's Wake Up") by its South African healthcare providers and patients involved in its development and design.

Masivukeni is designed to be used by lay adherence counselors during the counseling sessions with patients as both a guide to the intervention curriculum (helping counselors know what content has and has not been covered with each patient), and a multimedia tool to convey complex information to patients in novel, easy-to-understand formats (for an overview of the intervention design see: https://www.youtube.com/watch?v=MOGlicrnko0). Elsewhere, we have extensively described the process of adaptation and development of the intervention for the South African context and reported its high acceptability by patients, counselors, and clinic administrators, as well as the feasibility of its use in a busy resource-constrained healthcare setting [35]. Table 1 shows the curriculum, objectives, and activities for each session of Masivukeni.

Masivukeni's multimedia foundation was programmed in HTML and is presented in a webpage format, but an internet connection is not required to administer the intervention. Only minimal computer literacy is required to operate the program (i.e., knowledge of how to use a mouse and keyboard, open and close programs, and use a username and password). The user interface was designed to be simple and provide a roadmap for each session-through simple graphics, counselors can see quickly where they are in each session and which activities they have completed and have yet to complete. Counselors and patients can enter responses to questions and manipulate virtual objects in order to apply new concepts, explore hypothetical scenarios, practice new skills, test knowledge, and set goals for future sessions. Short videos are used to convey complex and difficult HIV information (e.g., drug resistance, ART adherence, and problemsolving approaches to address adherence barriers) and are easily viewed, paused, and reviewed at the patients' and/or counselor's discretion. Masivukeni also was programmed with embedded standardized mental health and substance use screening questions that provide standardized referral scripts for patients who have scores indicating the possible presence of such problems.

Activity completion information, as well as patient initiated and/or counselor initiated questions, are saved from session to session so that patients and counselors can review questions that were asked in previous sessions, and see which activities were completed previously and which ones still need to be done. The program records and tracks all data entered by the facilitator or patients, records the time that was spent on each activity, and can print a packet of information tailored to a particular patient's sessions.

We have previously reported that lay counselors using Masivukeni indicated that it helped them engage patients 
Table 1 Masivukeni sessions overview

\begin{tabular}{|c|c|c|}
\hline Session & Participant(s) & Objectives \\
\hline 1 & Patient & $\begin{array}{l}\text { Develop rapport and understanding of intervention goals } \\
\text { Screen for mental health and substance use problems and make necessary referrals } \\
\text { Assess other psychosocial needs related to HIV care and prevention } \\
\text { Increase commitment to medical (including medication) adherence } \\
\text { Review patient's social support network and identify a treatment support partner } \\
\text { Identify personal reasons for staying healthy } \\
\text { Multimedia activities } \\
\text { Mental health and substance use screening questions automatically score results and provide counselors with } \\
\text { severity appropriate scripts for referrals } \\
\text { Interactive: Support Tree Activity (visually and dynamically represents support network and who in the } \\
\text { network knows patient's HIV status and/or who can offer practical support) } \\
\text { Interactive: Reasons to stay healthy (visually depicts patient's top several reasons to stay healthy) }\end{array}$ \\
\hline 2 & $\begin{array}{l}\text { Patient and support } \\
\text { partner }\end{array}$ & $\begin{array}{l}\text { Develop rapport and understanding of intervention goals with partner } \\
\text { Increase knowledge of HIV, ART, resistance, and need for high levels of adherence } \\
\text { Review reasons for staying healthy; make changes if wanted } \\
\text { Multimedia activities } \\
\text { Interactive: Island Activity } 1 \text { (visually and dynamically depicts the relationship between CD4 count and viral } \\
\text { load } \\
\text { Interactive: Island Activity } 2 \text { (visually and dynamically depicts the relationship between ART adherence, CD4 } \\
\text { count and viral load) } \\
\text { Interactive: Pill Regimen Activity (visually and dynamically represents number of pills in patient ART } \\
\text { regimen and dosing times) } \\
\text { Video: Dramatically illustrate viral resistance and the importance of adherence using snakes to represent HIV } \\
\text { and soldiers to represent the immune system } \\
\text { Interactive: Reasons to stay healthy (visually depicts patient's top several reasons to stay healthy) }\end{array}$ \\
\hline 3 & $\begin{array}{l}\text { Patient and support } \\
\text { partner }\end{array}$ & $\begin{array}{l}\text { Reinforce importance of adherence and good health care } \\
\text { Promote adherence self-efficacy } \\
\text { Teach problem-solving skills and how to apply them to adherence barriers } \\
\text { Review reasons for staying healthy; make changes if wanted } \\
\text { Multimedia activities } \\
\text { Video: Demonstration of problem-solving for ART adherence with South African actors } \\
\text { Interactive: Problem-solving Activity (choose barriers from menu and complete action plan) }\end{array}$ \\
\hline 4 & $\begin{array}{l}\text { Patient and support } \\
\text { partner }\end{array}$ & $\begin{array}{l}\text { Practice problem-solving } \\
\text { Review modes of HIV transmission and importance of HIV transmission prevention } \\
\text { Review reasons for staying healthy; make changes if wanted } \\
\text { Multimedia activities } \\
\text { Game: HIV "Myth/Fact" (patient and partner are given statements about HIV transmission and asked to } \\
\text { determine if they are true or false }\end{array}$ \\
\hline 5 & $\begin{array}{l}\text { Patient and support } \\
\text { partner }\end{array}$ & $\begin{array}{l}\text { Practice problem-solving } \\
\text { Discuss the importance of thoughtful disclosure and how it can benefit adherence } \\
\text { Multimedia activities } \\
\text { Video: Dramatic portrayals of Hope and Joseph where Hope enlists the help of her brother to help her stay } \\
\text { adherent and Joseph hides his HIV status and medications from his family. Hope stays healthy and Joseph } \\
\text { falls very ill }\end{array}$ \\
\hline 6 & $\begin{array}{l}\text { Patient and support } \\
\text { partner }\end{array}$ & $\begin{array}{l}\text { Build support and confidence to access and communicate with members of the healthcare team } \\
\text { Review the Support Tree and make any changes/additions } \\
\text { Review other activities as per counselor discretion and/or patient request } \\
\text { End program with patient and support partner committing to help each other stay healthy } \\
\text { Multimedia activities } \\
\text { Use of any previous activity or video as needed }\end{array}$ \\
\hline
\end{tabular}


better than the standard counseling methods and procedures; stay on track with the intervention content, curriculum and health messages; and remember to cover important information and material [35]. In this report, we present a first analysis of the impact of Masivukeni on ART adherence outcomes and the behavior change mediators hypothesized within our theoretical framework, Social Action Theory [36], in a pilot sample of HIV-infected patients taking antiretroviral medication (ARVs) at one public health clinic in South Africa.

\section{Method}

\section{Participants and Procedures}

The study was conducted between August, 2008, and April, 2010, at a City of Cape Town Department of Health primary health clinic that provides HIV care and ART and is located near a large township. Eligible patients were $\mathrm{HIV}+, 18$ years or older, on ART for at least 6 months, identified as nonadherent $(<90 \%$ adherence by clinic-based pill count, detectable viral load, or other clinical signs of non-adherence, such as the presence of opportunistic infections and other HIV-related medical comorbidities as identified by the patient's provider and/or medical record), and willing to bring a treatment support partner ("buddy") to counseling sessions. The clinic policy at that time followed the City of Cape Town Department of Health (DOH) requirements requiring all patients receiving $\mathrm{ART}$ adherence counseling to bring a treatment support partner to counseling sessions. This often meant that patients would ask another available patient they met in the waiting room to attend their session with them [35]. In practice, counselors were able to counsel some patients if they did not bring a buddy. Clinic staff offered participation in this study to potentially eligible patients who, having been non-adherent, were being asked to come back to the clinic for additional ART counseling sessions. Interested patients then met with the study coordinator who described the study and conducted eligibility screening. Sixty-five participants were recruited and enrolled in the study. After the study coordinator obtained informed consent, the participant completed a baseline assessment (approximately $90 \mathrm{~min}$; see Measures) administered by study staff, and was then randomized to receive either Masivukeni or SOC counseling. The study statistician generated a randomization list that was provided to the South African Project Director (PD) to use to assign participants to the appropriate study arm. The PD remained blind to the next assignment until after eligibility, consent, and baseline assessment were completed.

Patients in the Masivukeni condition completed the first session of their 6-session non-adherence counseling immediately or were scheduled to return to the clinic to complete within 2 weeks. Sessions were then scheduled approximately 1 week apart. If a patient randomized to Masivukeni did not return for a scheduled session, the study counselor called and/or texted him/her to reschedule the session. At the time of the study, no standardized counseling curriculum existed for counseling patients who were having problems with medication adherence, thus leaving the SOC counselors to address adherence issues in whatever manner they decided was needed for the patient.

All participants completed a post-intervention assessment; those in the Masivukeni group completed it immediately after their final counseling session, which ranged from 5 to 6 weeks after their baseline assessment. To establish equivalent timing (relative to baseline assessment) of the post-intervention assessment between groups, those in the SOC group completed it approximately 5-6 weeks after their first SOC counseling session (calculated from the day of study enrollment).

Participants in both arms received compensation for transportation (approximately $\$ 5$ equivalent) to and from each counseling session, and compensation (another approximately $\$ 5$ equivalent) for completing the assessment. All procedures received approval from the Human Research Ethics Committee of the University of Cape Town and the Institutional Review Board of the New York State Psychiatric Institute.

\section{Masivukeni Intervention}

To administer the Masivukeni intervention, we hired two lay counselors who had received adherence counseling and HIV testing and counseling training from the local NGO (see standard of care below) and had previous experience working in clinics conducting HIV testing and counseling, as well as ART adherence counseling. They were trained in the use of Masivukeni (i.e., how to operate the program and navigate through the intervention) and how to integrate their current adherence counseling skills and knowledge with Masivukeni. We have described in detail the content of the six-session Masivukeni intervention previously [35], and Table 1 provides an overview of the content and curriculum. In the first Masivukeni session, the counselor was guided by the computerized program (see Figs. 1 and 2) in administering standardized screening assessments for psychiatric distress and problems with alcohol and substance use. Scores were automatically and immediately provided, along with scripted messages to give to the patient tailored to level of impairment, if any. The session was also focused on selecting an optimal support partner by using the interactive Support Tree Activity Fig. 3. The participant then invited the treatment support partner to attend the remaining five Masivukeni sessions in which the counselor used the laptop computer to 
guide the counseling; engage the patient and support partner with short videos and multimedia, interactive activities to illustrate and explain complex HIV medical information and behavioral components of adherence; and identify and problem-solve adherence barriers specific to the patient (Figs. 4-6). The support partner was encouraged to come back to the remaining sessions.

\section{Standard of Care}

SOC counselors were the existing staff counselors at the clinic site (who had also received the same adherence counseling, as well as HIV testing and counseling training through the local NGO). Because there was no standard counseling curriculum for patients with adherence problems, participants randomized to SOC non-adherence counseling met with the SOC counselors as often and for as long as the counselor deemed necessary, which in practice often amounted to a single, brief ( $<15 \mathrm{~min}$ ) session. The SOC counseling curriculum consisted of information about HIV disease, ARVs, the importance of adherence, resistance, and healthy living and was typically presented via a flipchart. While it is the policy of the $\mathrm{DOH}$ to have a treatment buddy attend adherence counseling sessions with the index patient, in actual practice, many SOC counselors allowed counseling to occur without a treatment partner being present or allowing the patient to bring in a "partner" whom the patient was able to recruit from the waiting room (not necessarily a person in their social network).

\section{Measures}

The assessment battery was developed by a combined USSouth Africa team of investigators in accordance with Social Action Theory (SAT; see Fig. 7) [36, 37], which posits that behavioral health outcomes are mediated by contextual factors (e.g., demographics, health care systems, and mental health) and by self- and social-regulation factors (e.g., self-efficacy, health beliefs, social relationships, and stigma). All measures were translated from English into Xhosa and back-translated by linguistic experts at the University of Cape Town. They were also reviewed by Xhosa-speaking study staff to ensure accurate and meaningful translations. All assessments were administered by trained research assistants.

\section{Contextual Influences}

Demographic and medical information was obtained by participant self-report. Participants were asked when they were diagnosed with HIV, how long they had been on ARVs, their most recent CD4 count (if known), and standard demographic questions (e.g., age, education, etc.).

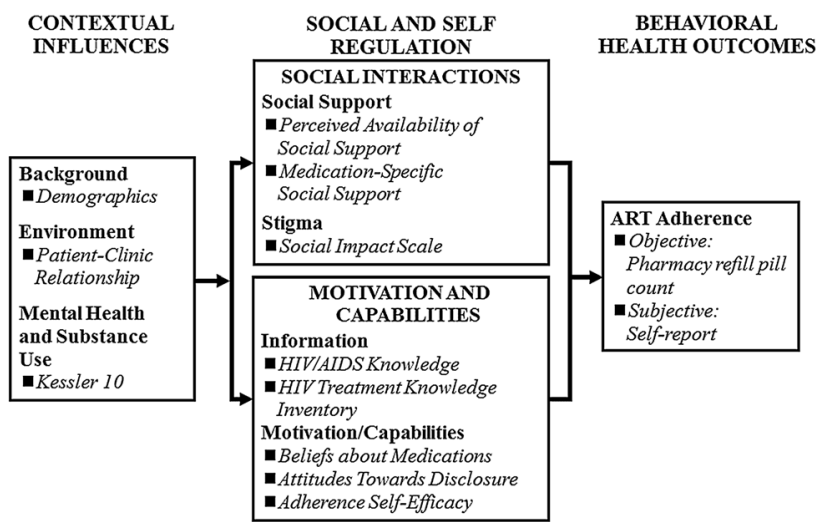

Fig. 1 Adapted social action theory constructs and accompanying measures (italics)

Clinic-patient relationship was assessed with 12 items via a 4-point scale ("Never" to "Every time") adapted from the Physician-Patient Relationship Quality Scale [38] in which participants were asked to rate how they felt about their experience receiving care from the clinic (for example, How often do you "Feel that the clinic staff really listens to your concerns?" and "Get asked by the clinic staff about how well you are able to take your medications as prescribed."). Items were summed to create a total score in which higher scores reflected more positive clinicpatient relationships. Cronbach's $\alpha=0.90$ for this sample.

Mental health was assessed with the Kessler 10 (K10) [39, 40], which assesses general mental health functioning via 10 items with a 5-point Likert-type scale ("None of the time" to "All of the time"). Sample items include, "During the past month, that is from [date one month ago] to yesterday, about how often did you feel:...," "Tired out for no good reason," and, "Worthless." Items were summed to create a total K10 score in which higher scores indicated more psychiatric distress. Cronbach's $\alpha=0.84$ for this sample.

\section{Self-Regulation}

Adherence self-efficacy was assessed via 14 items from the AACTG adherence instruments [41]. Participants were asked to rate how confident they would be in taking their medications in different circumstances (e.g., when busy, feeling healthy, drinking alcohol, etc.) on a 5-point likert-type scale ranging from "Not at all confident" to "Completely confident." Items were summed to create a total adherence self-efficacy score in which higher scores indicated more selfefficacy. Cronbach's $\alpha=0.84$ for this sample.

Attitudes towards disclosure was assessed via five items that asked participants how much they agreed or disagreed (on a 4-point Likert-type scale where $1=$ Strongly disagree and $4=$ strongly agree) with statements such as "In general, disclosing my HIV status to other people in my 
Fig. 2 Intervention home page. The Homepage lists all the sessions. When counselors click on a Session box, they are taken to the Session page (see Fig. 3). When all the activities in a session are complete, the session box turns green. This helps counselors know where they are in the intervention and which sessions have been completed (Color figure online)
Fig. 3 Session page user interface. The Session page displays the goals of the session as well as the list of activities. Counselors and patients are able to see how many activities are in the session, and which ones have been completed (Activity box turns green when complete). This helps counselors know where they are in the intervention and which sessions have been completed (Color figure online)

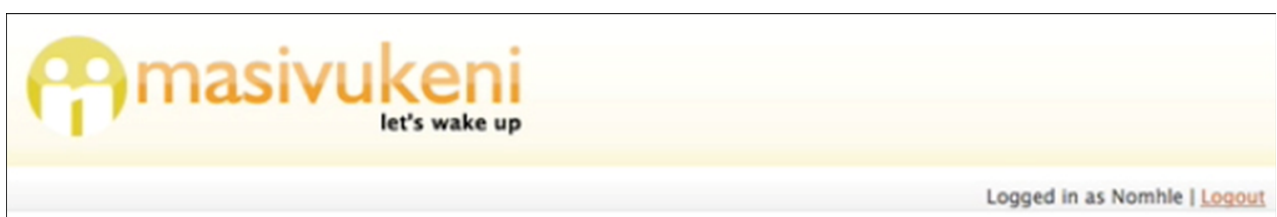

\section{Session List}

Click on a session number to continue with the intervention. The suggested next session is highlighted.
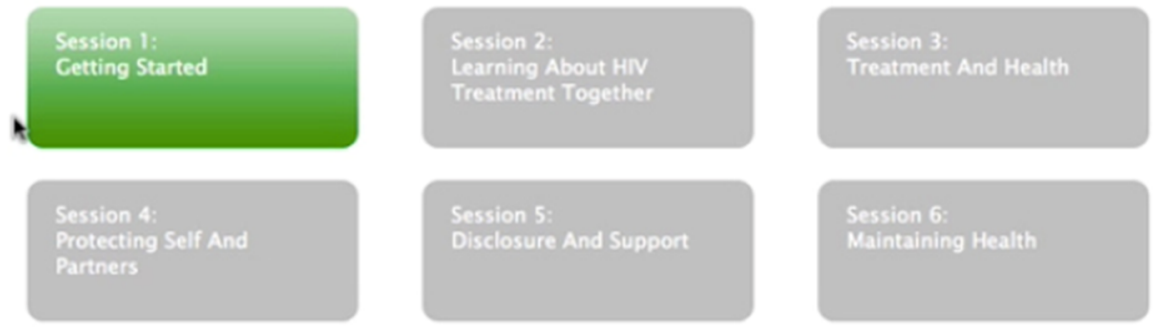

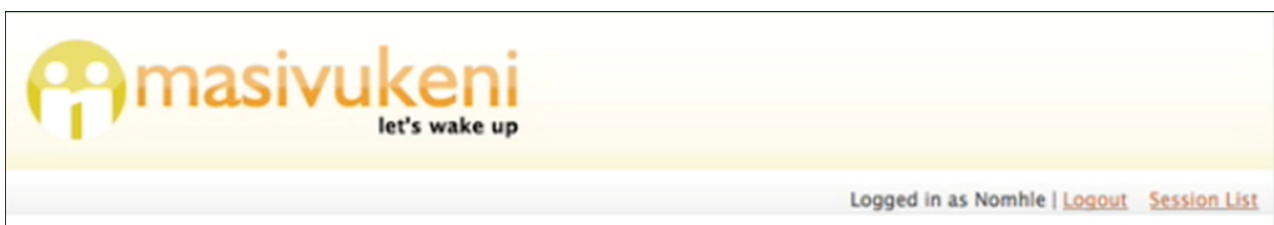

\section{Session 1: Getting Started}

\section{Agenda}

The main goals of the first session are to:

1. Introduce the participant to the intervention-the main goals, schedule, and ground rules:

2. Conduct screening for mental health problems so that the participant can be referred if necessary: and

3. Introduce the important role of the social network and support in promoting adherence.

$8 y$ the end of the session you will help the participant select a support partner, who will participate in the intervention for sessions 2.6.

Click on an activity to continue with this session. The suggested next activity is highlighted.
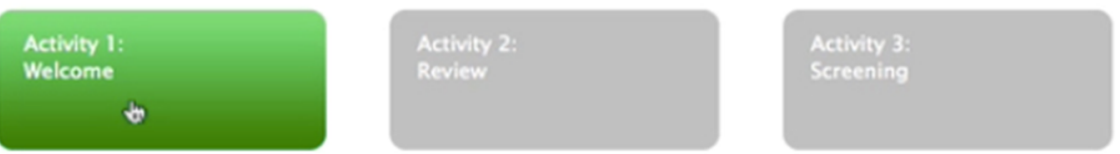

Activity 6 :

Treatment Buddy 
Fig. 4 Support Tree Activity. Orange colored tree fruits indicate disclosure status (orange $=$ disclosed to). The purple ring around the fruit indicates that the person is a source of practical support (Color figure online)

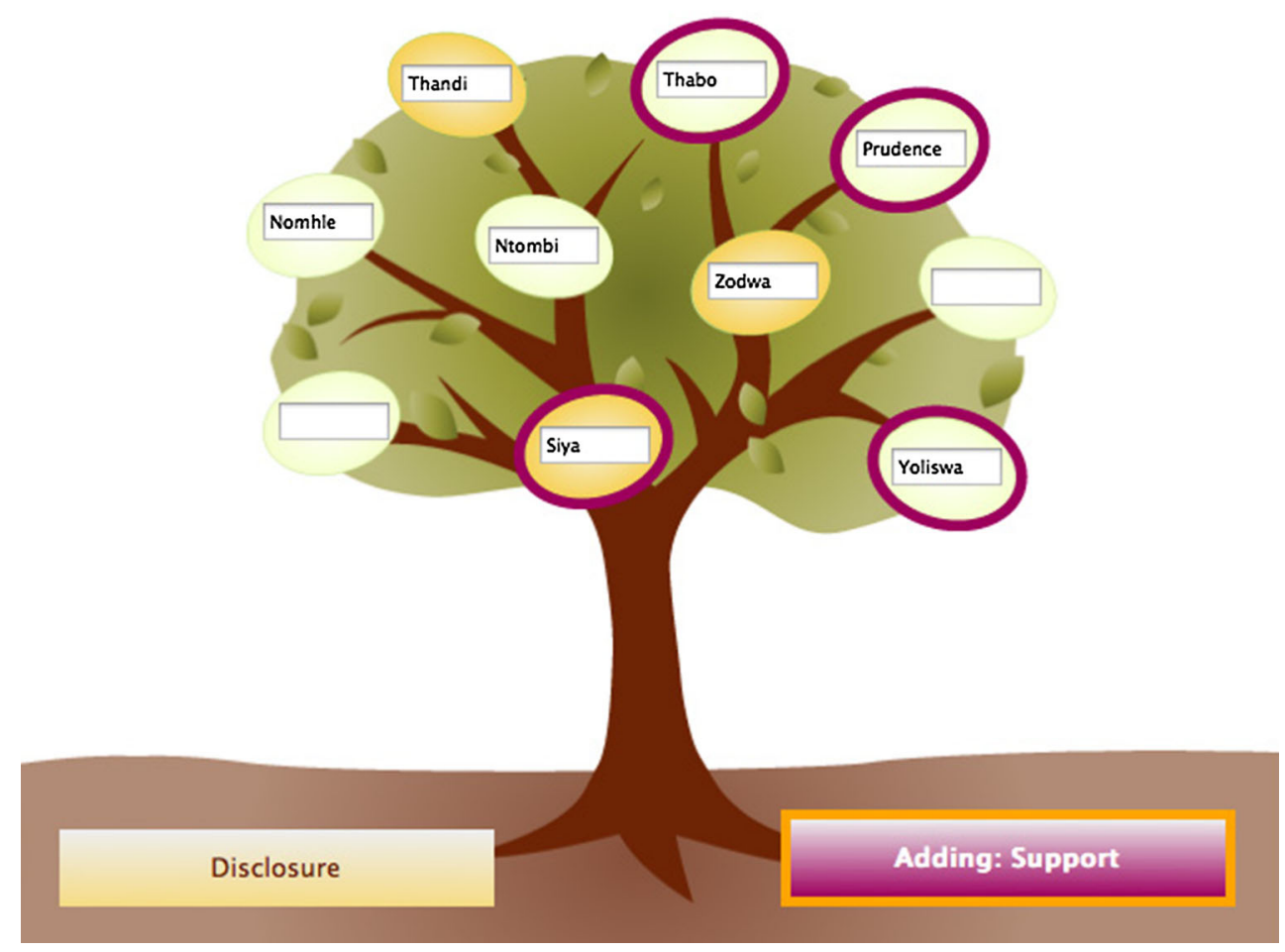

Fig. 5 HIV Knowledge (Island) Activity. Patients and partners can move the sliders up and down. As viral load goes up and cd4 count goes down, the person on the island becomes thinner and the water level rises

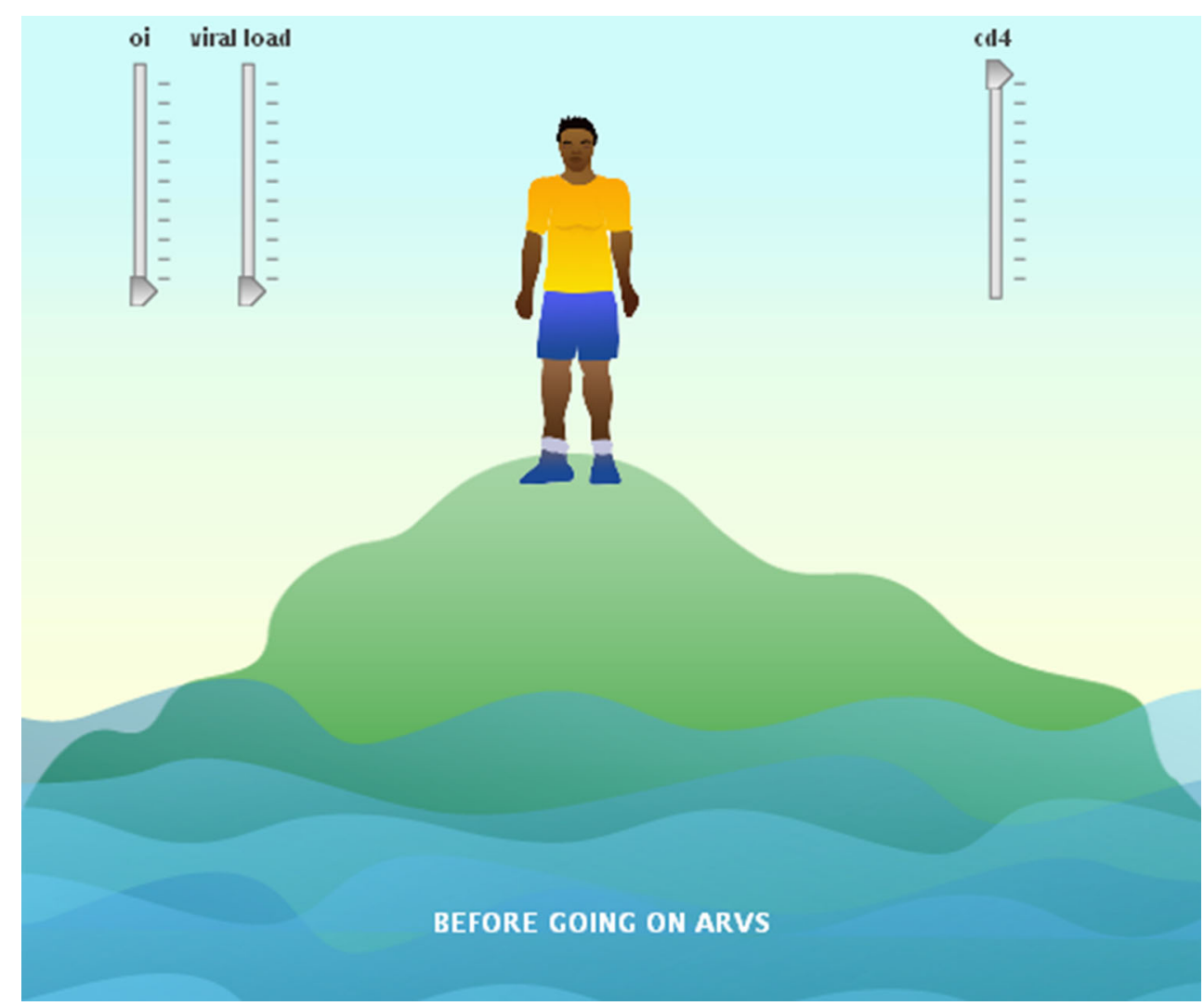

community can be helpful to me," and, "I find it easy to disclose my HIV status to other people." Items were summed to create a total score (with two items being reverse-scored) in which higher scores indicated more favorable attitudes towards disclosing one's HIV status. Cronbach's $\alpha=0.62$ for this sample. 
Fig. 6 HIV Knowledge (Island) Activity 2. Patients and partners can move the adherence slider up and down. As adherence goes up, viral load goes down, cd4 count goes up, and the person on the island becomes moves up the mountainside

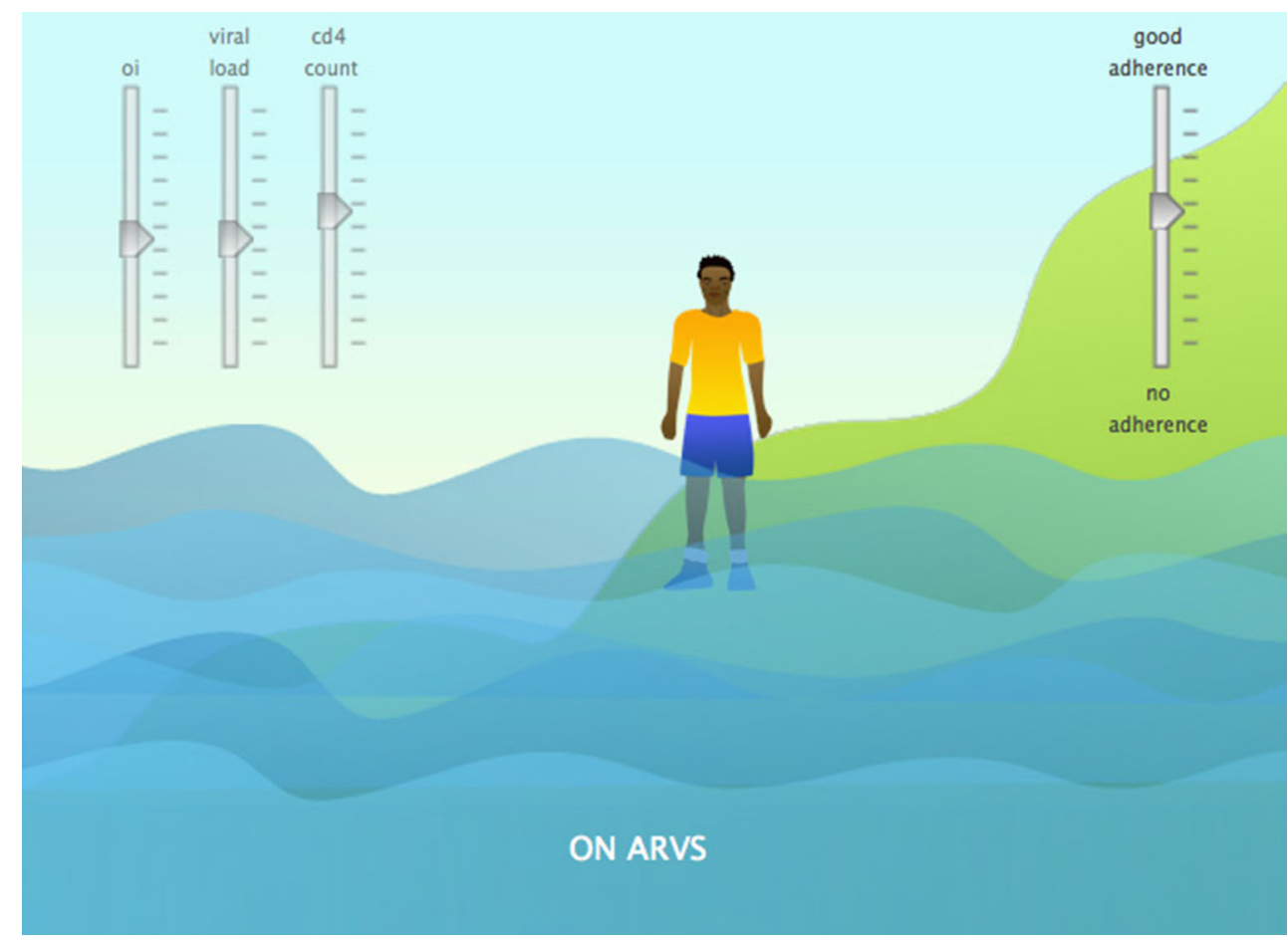

Activity 2: Pill Regimen Activity

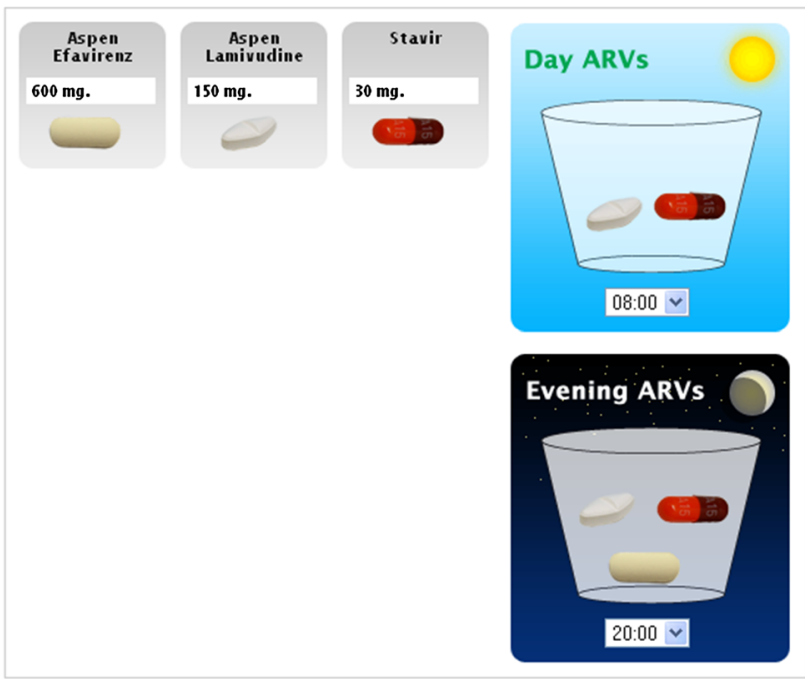

Fig. 7 Pill Regimen Activity. Patients and partners can move their regimen pills into the cups. If they make mistakes, the counselor will correct them

Beliefs about medications was assessed by the 5-item Necessity Subscale from the Beliefs about Medication Scale [42] that assesses individual views about HIV medications (Part A) and personal views on medications in general (Part B). Higher scores on the Necessity Subscale indicate stronger beliefs that ARVs are important and the benefits of ARVs outweigh their challenges. Cronbach's $\alpha=0.60$ for this sample.
HIV/AIDS knowledge was assessed via the 11-item HIV/ AIDS Knowledge Inventory [43]. Participants were asked specific questions about what causes HIV and how it is transmitted (e.g., "Is HIV the virus that causes AIDS?" and "Is HIV/AIDS spread by kissing?") and given the response options of "Yes," "No," and "Don't know." A total score was computed, such that higher scores indicated more correct knowledge of the disease and how it is transmitted. Cronbach's $\alpha=0.69$ for this sample.

HIV Treatment Knowledge was assessed by the 12-item HIV/AIDS Treatment Knowledge Inventory [44, 45]. Participants were asked to respond "True," "False," or "Don't Know" to statements about ART and other aspects of HIV treatment, such as "CD4 counts are used to measure immune system functioning," and "Taking antiretroviral therapy exactly as prescribed is likely to reduce viral load." A total score was computed such that higher scores indicated more correct knowledge about HIV/AIDS treatment. Cronbach's $\alpha=0.67$ for this sample.

\section{Social-Regulation}

Medication-specific social support was assessed via 8 items, each with a 5-point Likert-type scale ("Never" to "Very often") [46]. Individuals were asked, "How often has someone in the past three months....." "Helped you monitor your symptoms and medication side effects?" and "Checked in with you about your medications?" Items were summed (and reverse-coded when necessary) to 
create a total score in which higher scores indicated more support. Cronbach's $\alpha=0.88$ for this sample.

Perceived availability of social support was assessed via an 8-item scale [47, 48] asking on a 5-point Likert-type scale ("Definitely No" to "Definitely Yes") how likely the respondent would be able to get different types of support. Example items are, "Is there someone you could contact if you wanted to talk about an important personal problem you were having?" and "Is there someone you could turn to if you needed to borrow $\$ 10$, get a ride to the doctor, or some other small immediate help?" Items were summed (and reverse-coded when necessary) to create a total score in which higher scores indicated more perceived social support. Cronbach's $\alpha=0.82$ for this sample.

$H I V$-related stigma was assessed via the 9-item Social Rejection subscale of the Social Impact Scale [49]. Individuals were asked to agree or disagree (on a 5-point Likert-type scale) with statements about their experiences of other people since becoming infected with HIV. For example, items asked, "I feel that I have been treated with less respect than usual by others," "I feel some friends have rejected me because of my illness," and, "Due to my illness, others seem to feel awkward and tense when they are around me." Items were summed (and reverse-coded when necessary) to create a total score in which higher scores indicated more stigma related social rejection. Cronbach's $\alpha=0.81$ for this sample.

\section{Behavioral Health Outcomes}

Objective ART adherence was measured by the standard clinic-based pill count as established by the clinic pharmacy and City Department of Health and conducted at each pharmacy ARV refill. The pharmacist formula for calculating percent adherence was as follows: antiretroviral medications as your doctor prescribed them?" [41]. Responses ranged from "All of the time" to "None of the time." A short preamble to the question reminded participants that many people struggle taking their ARVs as prescribed.

\section{Data Analysis}

Descriptive statistics were generated overall and by group for all SAT constructs: self- and social-regulation, contextual factors, and behavioral health outcomes at baseline. This small pilot study was not powered to determine intervention efficacy but rather to evaluate acceptability and feasibility of the intervention and to determine whether there were any changes in the desired direction in the proposed mediators and behavioral outcomes. Therefore, for this report, we provide routine point estimates and confidence intervals to evaluate parameter values that would not be ruled out by the pilot results. We compared Masivukeni participants to SOC participants in terms of their mean change from baseline to post-intervention in medication adherence measured by clinic-based pill count and self-reported adherence, self- and social-regulation, and contextual factors. We used generalized linear models (GLM) with identity link function to examine the change over time. The model included the group indicator for Masivukeni (vs. SOC), the indicator for time (baseline vs. post-intervention), and the interaction of the two indicators. The regression coefficient corresponding to the group-bytime interaction term estimates the difference between the two study group populations' mean changes in study outcomes over time and, thus, represents the effect of the Masivukeni intervention on change in the outcomes of interest. We employed generalized estimating equations (GEE) to account for the effect of intra-cluster correlations

(Number of pills out from previous refill) - (Number of pills in at current refill)

(Days since last refill $) \times($ Number of pills prescribed per day)

An adherence percentage was calculated for each medication in the regimen with higher percentage indicating higher adherence. For this study, we compared the clinicbased pill count data for the 30-day period prior to enrolling in the study and the clinic-based pill count data at the refill period closest to the 1-month follow-up time point.

Self-report ART adherence was assessed with one item from the AACTG asking participants to rate their adherence over the past 4 weeks "Thinking about the past 4 weeks, how often did you take all of your HIV introduced by multiple assessments on the same participant.

\section{Results}

Participants

Table 2 presents the overall demographics and self-reported medical history of enrolled participants. There were no 
Table 2 Participant

characteristics
There were no significant differences between groups

\begin{tabular}{|c|c|c|c|c|}
\hline & \multicolumn{2}{|c|}{ Control $(\mathrm{N}=32)$} & \multicolumn{2}{|c|}{ Intervention $(\mathrm{N}=33)$} \\
\hline & $\begin{array}{l}\text { Mean or } \\
\text { percent }\end{array}$ & $\mathrm{SD}$ or $\mathrm{N}$ & $\begin{array}{l}\text { Mean or } \\
\text { percent }\end{array}$ & $\mathrm{SD}$ or $\mathrm{N}$ \\
\hline Age (in years) & 38.46 & 9.11 & 38.46 & 9.11 \\
\hline Percent female & $66 \%$ & 21 & $67 \%$ & 22 \\
\hline Percent completed high school & $3 \%$ & 1 & $0 \%$ & 0 \\
\hline Percent currently employed & $9 \%$ & 3 & $9 \%$ & 3 \\
\hline Percent currently in a relationship & $53 \%$ & 17 & $30 \%$ & 10 \\
\hline Percent no food at least once in past month & $47 \%$ & 15 & $28 \%$ & 16 \\
\hline Years since HIV diagnosis & 5.59 & 3.54 & 5.59 & 3.54 \\
\hline Years on antiretroviral therapy & 3.34 & 2.74 & 3.34 & 2.74 \\
\hline Self-reported most recent CD4 count & 259 & 138 & 259 & 138 \\
\hline
\end{tabular}

differences in demographic and medical variables between intervention groups. All participants were Black, and $94 \%$ spoke Xhosa at home. Most participants were on the currently available (at the time of this study) first-line ARV regimen, which consisted of 3TC (1 pill twice per day), D4T (1 pill twice per day), and efavirenz (1 pill once per day) or neviropine ( 2 pills twice per day), for a total pill burden of 5-6 pills per day with two dosing times per day. Fixed dose combinations were not available to any patients during the course of this study. Eleven participants were prescribed second line regimens, most consisting of DDI (either $50 \mathrm{mg}$ or $100 \mathrm{mg}$, twice per day) and Kaletra or Aluvia (4 pills, twice per day). There were no differences in regimens between groups.

Sixty-five participants were enrolled at baseline, 33 were randomized to receive Masivukeni and 32 to SOC. Eighty-five percent $(n=55)$ were retained at post-intervention. Of the 33 participants randomized to Masivukeni $27(82 \%)$ completed all six sessions and the post-intervention assessment. Of the 32 participants randomized to SOC, $28(88 \%)$ completed the post-intervention assessment. The most common reasons for study "drop-out" were moving out of the area, illness or hospitalization, conflict of clinic attendance with employment, and clinic loss to follow-up; most participants who did not complete a post-intervention assessment also did not return to the clinic for medication refills during that period. There were no differences between intervention arms on reasons for drop-out. In sum, we were able to complete the pilot study with $86 \%$ of participants who initially enrolled and $96 \%$ of participants who came to the first Masivukeni session.

\section{SAT Model Constructs}

Table 3 presents means for SAT model constructs grouped by domain. At baseline, there were no significant differences between the SOC and Masivukeni groups on any of the psychosocial or adherence measures. The point estimates of the Masivukeni intervention effect at post-intervention for all outcomes of interest are presented together with their $95 \%$ confidence intervals and corresponding $p$ values.

\section{Self-Regulation}

Adherence self-efficacy and attitudes towards disclosure increased in both groups between baseline and post-intervention. Only the increase in attitudes towards disclosure was statistically significantly different between the study arms, with participants in Masivukeni reporting significantly more positive attitudes towards disclosure at postintervention than participants in the SOC group. Positive beliefs about medication increased in the Masivukeni group and decreased in the SOC group. Though not statistically significant, the difference in change between the two groups was at a trend level $(p=0.15)$, and suggests that Masivukeni participants may have had more positive beliefs about ART than those in the SOC group after the intervention. HIV/AIDS knowledge also increased slightly in both groups, though there was no statistically significant difference between groups in this change. HIV treatment knowledge increased slightly in the Masivukeni group and decreased slightly in the SOC group, though these changes were not significantly different.

\section{Social-Regulation}

Among our measures of social-regulation, medication specific social support increased in both groups between baseline and post-intervention, with the increase in the Masivukeni group being statistically significantly greater than that in the SOC group, and those in the Masivuekni group reporting significantly more medication specific social support to take their ARVs at post-intervention assessment. 
Table 3 Baseline and post-intervention results between groups

\begin{tabular}{|c|c|c|c|c|c|c|c|c|c|c|c|}
\hline \multirow{4}{*}{$\begin{array}{l}\text { Variable } \\
\text { Higher scores = better, } \\
\text { except where noted }\end{array}$} & \multicolumn{4}{|c|}{ Baseline } & \multicolumn{4}{|c|}{ Post-intervention } & \multirow[t]{4}{*}{ Beta $^{a}$} & \multirow[t]{4}{*}{$95 \% \mathrm{CI}$} & \multirow[t]{4}{*}{$p^{\mathrm{a}}$} \\
\hline & \multirow{2}{*}{\multicolumn{2}{|c|}{$\frac{\text { Control }}{(\mathrm{n}=32)}$}} & \multirow{2}{*}{\multicolumn{2}{|c|}{$\frac{\text { Intervention }}{(\mathrm{n}=33)}$}} & \multirow{2}{*}{\multicolumn{2}{|c|}{$\frac{\text { Control }}{(\mathrm{n}=28)}$}} & \multirow{2}{*}{\multicolumn{2}{|c|}{$\frac{\text { Intervention }}{(\mathrm{n}=27)}$}} & & & \\
\hline & & & & & & & & & & & \\
\hline & Mean & SD & Mean & SD & Mean & SD & Mean & SD & & & \\
\hline \multicolumn{12}{|l|}{ Self-regulation } \\
\hline Adherence self-efficacy & 59.72 & $(9.14)$ & 60.14 & $(9.45)$ & 64.44 & $(5.96)$ & 63.79 & $(7.17)$ & -1.07 & $(-6.56,4.41)$ & 0.70 \\
\hline Attitudes towards disclosure & 10.07 & $(2.03)$ & 9.71 & $(2.38)$ & 10.81 & $(1.81)$ & 11.83 & $(1.78)$ & 1.38 & $(0.07,1.68)$ & 0.04 \\
\hline Beliefs about medications & 7.45 & $(3.48)$ & 7.64 & $(4.11)$ & 7.19 & $(2.66)$ & 8.96 & $(3.00)$ & 1.59 & $(-0.59,3.77)$ & 0.15 \\
\hline HIV/AIDS knowledge & 8.54 & $(0.58)$ & 8.58 & $(1.14)$ & 8.88 & $(0.54)$ & 8.76 & $(0.97)$ & -0.15 & $(-0.71,0.40)$ & 0.59 \\
\hline Treatment knowledge & 10.69 & $(0.81)$ & 9.94 & $(2.18)$ & 10.61 & $(1.23)$ & 10.45 & $(1.14)$ & 0.60 & $(-0.38,1.58)$ & 0.23 \\
\hline \multicolumn{12}{|l|}{ Social-regulation } \\
\hline Medication social support & 22.55 & $(7.88)$ & 21.50 & $(8.53)$ & 24.30 & $(7.18)$ & 28.00 & $(7.25)$ & 4.75 & $(0.77,8.74)$ & 0.02 \\
\hline Perceived availability of social support & 30.28 & $(6.53)$ & 28.94 & $(7.25)$ & 31.82 & $(4.46)$ & 32.68 & $(6.69)$ & 2.20 & $(-1.27,5.66)$ & 0.21 \\
\hline $\begin{array}{l}\text { Stigma/Social Rejection } \\
\text { Scale (higher }=\text { worse) }\end{array}$ & 18.42 & $(4.20)$ & 18.69 & $(4.80)$ & 19.58 & $(4.61)$ & 16.92 & $(3.88)$ & -2.93 & $(-5.29,-0.56)$ & 0.02 \\
\hline \multicolumn{12}{|l|}{ Contextual influences } \\
\hline Clinic-patient relationship & 35.41 & $(7.05)$ & 36.00 & $(9.36)$ & 35.48 & $(6.33)$ & 40.38 & $(5.14)$ & 4.31 & $(0.05,8.57)$ & 0.05 \\
\hline Mental health problems (higher $=$ worse) & 19.31 & $(7.93)$ & 16.62 & $(5.60)$ & 14.35 & $(6.62)$ & 13.50 & $(3.97)$ & 1.85 & $(-1.82,5.51)$ & 0.32 \\
\hline \multicolumn{12}{|l|}{ Behavioral health } \\
\hline $\begin{array}{l}\text { Objective adherence } \\
\text { (clinic-based pill counts) }^{\mathrm{b}}\end{array}$ & 66.26 & $(24.53)$ & 63.70 & (21.69) & 58.39 & $(22.60)$ & 74.21 & $(25.13)$ & 0.18 & $(-0.08,0.45)$ & 0.17 \\
\hline Self-reported adherence & 4.28 & $(1.22)$ & 4.29 & $(1.19)$ & 4.54 & $(0.99)$ & 4.57 & $(1.16)$ & -0.01 & $(-0.80,0.77)$ & 0.97 \\
\hline
\end{tabular}

${ }^{a}$ Beta represents the difference of mean change over time (from baseline to 1-month post-intervention) between Masivukeni and SOC, where $p$ is the $p$ value corresponds to whether the difference in beta is significantly different from 0

${ }^{\mathrm{b}}$ From pill count data, represents 1 month before and after baseline interview, respectively. This is also on a subset of full sample ( $\mathrm{n}=20$ )

Perceived availability of social support also slightly increased in both groups, but the difference in these changes between groups was not statistically significant. On our measure of HIV related stigma, participants in the Masivukeni group showed significantly greater decreases in social rejection at post-intervention than did participants in the SOC group. At post-intervention, those in the Masivukeni group reported greater decreases in HIV-related social rejection than did those in the SOC group.

\section{Contextual Influences}

Among our measures of contextual influences, scores on clinic-patient relationship did not increase in the SOC group between baseline and post-intervention, but increased by almost five points in the Masivukeni group. This difference in the changes between groups approached statistical significance $(p=0.05)$ and suggests that the Masivukeni patients developed a better, more positive relationship with the clinic than did participants in the SOC group. Scores on the mental health scale decreased in both groups between baseline and post-intervention, though the difference in the changes between groups was not statistically significant.

\section{Behavioral Health Outcomes}

Due to incomplete and/or missing pill count records in the clinic, we were only able to include a subsample of 20 (10 per group) in the analysis of objective adherence based on clinic-based pill count records. The analysis suggested that Masivukeni participants' adherence improved by $10 \%$, while SOC participants' adherence declined by $8 \%$, and the difference in these changes between groups was at the trend level of difference $(p=0.17)$. The proportion of participants who achieved $80 \%$ adherence or greater at post-intervention, based on the clinic-based pill counts, was $67 \%$ among Masivukeni participants and $16 \%$ among SOC participants $(p<0.05)$. Self-reported adherence increased slightly in both groups, but the difference in the changes between groups was not statistically significant, and, at both time points, mean scores approached the ceiling of the measure with most participants reporting very high adherence at baseline and post-intervention.

\section{Discussion}

In this pilot study, we set out to make preliminary comparisons of a multimedia-based, lay counselor-delivered 
adherence intervention with standard of care (SOC) ART adherence counseling for patients who were experiencing medication adherence problems. We have previously described the feasibility of Masivukeni and its high acceptability among patients, lay counselors, and clinic administrators [34]. Here, we report that, at post-intervention, those in the Masivukeni arm had increased medication adherence, whereas those in the SOC arm had decreased adherence. Though these changes in adherence rates between groups were not statistically different at postintervention, they point to an important trend that warrants further investigation. We also found significant differences and trend differences in several variables embedded in SAT, that were hypothesized to be mediators of changes in adherence behaviors, including contextual influences and self- and social-regulation (see Table 3 ). These were factors that were addressed in Masivukeni, thus providing preliminary evidence that this intervention shows promise in addressing important psychosocial factors that can lead to improved patient outcomes. Since this was a pilot feasibility study, lacking sufficient sample size and thus power to test efficacy, we cannot generalize from these findings. Nevertheless, we are optimistic about the potential of Masivukeni to show a range of significant differences in a larger randomized controlled trial (currently underway in South Africa).

While findings from this pilot study suggest that Masivukeni holds promise as an effective ART adherence intervention to improve behavioral adherence and important psychosocial influences on ART adherence, we also note several study limitations. First, the pilot study was conducted at only one clinic site and with a small sample, thus findings cannot be generalized to the larger patient population in the region. Second, for the objective adherence outcome measure, our sample size was further restricted because clinic-based pill count data were not available on all participants. Furthermore, the pill count data that was available to use may be inaccurate due to pill dumping. Hence, we must interpret the findings from the pill count data with caution. In fact, we have since learned that the City of Cape Town is exploring other measures of adherence because of the difficulties that clinic pharmacies are having conducting consistent and accurate pill counts. Third, this was the first time many of the measures in this study were used with this population. Hence, further research is needed to further validate these measures within this population. Finally, our study did not assess long-term effects of Masivukeni, and it is widely known that behavioral interventions often show steep declines in effectiveness at longer post-intervention follow-up periods [50]. Evaluation of longer-term effects of Masivukeni is the subject of our larger randomized controlled trial currently in the field.
Adherence rates in both study arms, even after the intervention, were low and on average far below the optimal $95 \%$ recommended adherence rate. This is likely because participants in the study were among the sickest and most challenged with adherence. Nevertheless, even a $10 \%$ increase in adherence, like we observed, with highly potent regimens has the potential to improve clinical outcomes. Furthermore, the proportion of participants achieving $80 \%$ adherence or greater was much higher among Masivukeni than SOC participants. With the hopeful advent of more potent and forgiving regimens, $80 \%$ adherence may be able to help individuals achieve viral suppression.

Technologies, such as Masivukeni, have the potential to enhance quality assurance of adherence counseling. For example, in the Western Cape Region, many lay counselors do not receive consistent and regular supervision due to limited resources. In Masivukeni, sophisticated computer programming tracks and records delivery of and time spent on key intervention components. In addition to documenting which counselors met with which study participants, the Masivukeni program records which activities have been completed (or missed) and the time spent on each task for each patient.

Masivukeni has built-in mental health and substance-use screening tools that guide the counselor in administering standard screening assessments and delivering scripts that are tailored to the patient's score and level of distress or impairment. Masivukeni keeps track of high scores on these screening tools and whether an appropriate referral was made. These types of process and screening tools, which are relatively simple to include during initial software development, can assist clinic administrators in ensuring that counselors are spending appropriate amounts of time with patients and covering all of the intervention activities. Clinic administrators can then use these data to correct lapses in patients' receipt of counseling services and thus improve service delivery. These technological tools have the potential for applicability across a wide range of health conditions and healthcare settings.

It has been documented that interactive video enhances transfer of learning and has produced health improvements in the management of chronic illness [51, 52]; and Masivukeni's computer-based tool includes enhanced scripted text, imagery, animations, audio, and video to deliver critical information and concepts as well as to model desired behaviors. In our previous work, we found that the multimedia foundation of Masivukeni enables lay adherence counselors to deliver the intervention in an engaging and structured way while overcoming challenges associated with their own limited education, training, and supervision and their patients' low literacy levels [35]. Related, multimedia, computer-based interventions such as Masivukeni can maximize standardization of intervention 
delivery, even by counselors with varying backgrounds, training, and capacity, thus taking full advantage of the potential of task-shifting in the health care system. Technological solutions to ART adherence, such as Masivukeni, may prove cost-effective, feasible, and acceptable in resource-constrained settings, such as South Africa, and more importantly, may enhance the quality of lay counseling, which can help ART patients maintain better adherence and healthier lives.

Acknowledgments This research was supported by a grant from the National Institute of Mental Health (R34-MH082654; PI: R. H. Remien, Ph.D. Drs. Remien, Mellins, Robbins, and Warne are also supported by the HIV Center for Clinical and Behavioral Studies (P30-MH43520; PI: R. H. Remien, Ph.D.). The authors would like to thank the patients and staff at the Hout Bay Clinic for their invaluable support of and contributions to this study. The authors would also like to thank Victoria Mayer for her tireless efforts launching this study, and Lara Hoppe and Tanya Vollenhoven for managing the study.

\section{References}

1. Harrigan PR, Hertogs K, Verbiest W, et al. Baseline HIV drug resistance profile predicts response to ritonavir-saquinavir protease inhibitor therapy in a community setting. AIDS. 1999;13(14):1863-71.

2. Hertogs K, Bloor S, Kemp SD, et al. Phenotypic and genotypic analysis of clinical HIV-1 isolates reveals extensive protease inhibitor crossresistance: a survey of over 6000 samples. AIDS. 2000;14(9):1203-10.

3. Kozal M. Review: cross-resistance patterns among HIV protease inhibitors. AIDS Patient Care STDs. 2004;18(4):199-208.

4. Ives KJ, Jacobsen H, Galpin SA, et al. Emergence of resistant variants of HIV in vivo during monotherapy with the proteinase inhibitor saquinavir. J Antimicrob Chemother. 1997;39(6):771-9.

5. Mayers DL. Drug-resistant HIV-1. JAMA. 1998;279(24):2000-2.

6. Hogg RS, Heath K, Bangsberg D, et al. Intermittent use of triplecombination therapy is predictive of mortality at baseline and after 1 year of follow-up. AIDS. 2002;16(7):1051-8.

7. Mannheimer S, Friedland G, Matts J, Child C, Chesney M. The consistency of adherence to antiretroviral therapy predicts biologic outcomes for human immunodeficiency virus-infected persons in clinical trials. Clin Infect Dis. 2002;34(8):1115-21.

8. McNabb J, Ross JW, Abriola K, Turley C, Nightingale CH, Nicolau DP. Adherence to highly active antiretroviral therapy predicts virologic outcome at an inner-city human immunodeficiency virus clinic. Clin Infect Dis. 2001;33(5):700-5.

9. Mills EJ, Nachega JB, Buchan I, et al. Adherence to antiretroviral therapy in Sub-Saharan Africa and North America. JAMA. 2006;296(6):679-90.

10. Zachariah R, Teck R, Buhendwa $\mathrm{L}$, et al. Community support is associated with better antiretroviral treatment outcomes in a resource-limited rural district in Malawi. Trans R Soc Trop Med Hyg. 2007;101(1):79-84.

11. Nachega JB, Knowlton AR, Deluca A, et al. Treatment supporter to improve adherence to antiretroviral therapy in HIV-infected South African adults: a qualitative study. J Acquir Immune Defic Syndr. 2006;43:S127-33. doi:10.1097/01.qai.0000248349.25630. $3 \mathrm{~d}$.

12. Callaghan M, Ford N, Schneider H. A systematic review of task shifting for HIV treatment and care in Africa. Hum Resour Health. 2010;8(1):8.
13. Samb B, Celletti F, Holloway J, Van Damme W, De Cock K, Dybul M. Rapid expansion of the health workforce in response to the HIV epidemic. N Engl J Med. 2007;357(24):2510-4.

14. Walsh A, Ndubani P, Simbaya J, Dicker P, Brugha R. Task sharing in Zambia: HIV service scale-up compounds the human resource crisis. BMC Health Serv Res. 2010;10(1):272.

15. Lehmann U, Van Damme W, Barten F, Sanders D. Task shifting: the answer to the human resources crisis in Africa? Hum Resour Health. 2009;7(1):49.

16. Bosworth K, Espelage D, DuBay T, Daytner G, Karageorge K. Preliminary evaluation of a multimedia violence prevention program for adolescents. Am J Health Behav. 2000;24:268-80.

17. Bartholomew LK, Shegog R, Parcel GS, et al. Watch, discover, think, and act: a model for patient education program development. Patient Educ Couns. 2000;39(2):253-68.

18. Rubin DH, Leventhal JM, Sadock RT, et al. Educational intervention by computer in childhood asthma: a randomized clinical trial testing the use of a new teaching intervention in childhood asthma. Pediatrics. 1986;77:1-10.

19. Brown SJ, Lieberman DA, Gemeny BA, Fan YC, Wilson DM, Pasta DJ. Educational video game for juvenile diabetes: results of a controlled trial. Med Inform (Lond). 1997;22:77-89.

20. French D. Influence smoking cessation with computer-assisted instruction. AAOHN. 1986;34:391-4.

21. Tingen MS, Grimling LF, Bennet G, Gibson EM, Renew MM. A pilot study of preadolescents to evaluate a video game-based smoking prevention strategy. J Addict Nurs. 1997;9:118-24.

22. Fogarty L, Roter D, Larson S, Burke J, Gillespie J, Levy R. Patient adherence to HIV medication regimens: a review of published and abstract reports. Patient Educ Couns. 2002;46(2):93-108.

23. Reis J, Riley W, Baer J. Interactive multimedia preventive alcohol education: an evaluation of effectiveness with college students. J Educ Comput Res. 2000;23:41-65.

24. Schinke SP, Schwinn TM, Nola JD, Cole KC. Reducing the risk of alcohol use among urban youth: three-year effects of a computer-based intervention with and without parent involvement. J Stud Alcohol. 2004;65:443-9.

25. Bellis JM, Grimley DM, Alexander LR. Feasibility of a tailored intervention targeting STD-related behaviors. Am J Health Behav. 2002;26:378-85.

26. Brown-Peterside P, Redding CA, Ren L, Koblin BA. Acceptability of a stage-matched expert system intervention to increase condom use among women at high risk of HIV infection in New York City. AIDS Educ Prev. 2000;12:171-81.

27. Evans AD, Edmundson-Drane EW, Harris KK. Computer-assisted instruction: an effective instructional method for HIV prevention education? J Adolesc Health. 2000;26:244-51.

28. Knebel E. The use and effect of computer-based training. In: Project QA, editor. Operations research issue paper 1, vol. 2. Bethesda, MD: USAID; 2000.

29. Knebel E. A comparison of computer-based and standard training in the integrated management of childhood illness in Uganda. In: Project QA, editor. Operations research results. Bethesda, MD: USAID; 2002.

30. Noar SM, Black HG, Pierce LB. Efficacy of computer technology-based HIV prevention interventions: a meta-analysis. AIDS. 2009;23(1):107-15. doi:10.1097/QAD.0b013e32831c5500.

31. Fisher JD, Amico KR, Fisher WA, et al. Computer-based intervention in HIV clinical care setting improves antiretroviral adherence: the LifeWindows Project. AIDS Behav. 2011;15(8):1635-46.

32. Remien RH, Stirratt MJ, Dognin J, Day E, El-Bassel N, Warne P. Moving from theory to research to practice. Implementing an effective dyadic intervention to improve antiretroviral adherence for clinic patients. J Acquir Immune Defic Syndr. 2006;43(Suppl 1): S69-78. 
33. Remien RH, Stirratt MJ, Dolezal C, et al. Couple-focused support to improve HIV medication adherence: a randomized controlled trial. AIDS. 2005;19(8):807-14.

34. Moretti F, Witte SS. Using new media to improve learning: multimedia connect for HIV/AIDS risk reduction and the triangle initiative. In: Wallace B, editor. Toward equity in health: a new approach to global health disparities. New York: Springer; 2007. p. $277-96$.

35. Remien RH, Mellins CA, Robbins RN, Kelsey R, Rowe J, Warne P, Chowdhury J, Lalkhen N, Hoppe L, Abrams EJ, El-Bassel N, Witte S, Stein DJ. Masivukeni: development of a multimedia based antiretroviral therapy adherence intervention for counselors and patients in South Africa. AIDS Behav. 2013;17:1979-91. doi:10.1007/s10461-013-0438-8.

36. Ewart CK. Social action theory for a public health psychology. Am Psychol. 1991;46(9):931-46.

37. Traube DE, Holloway IW, Smith L. Theory development for HIV behavioral health: empirical validation of behavior health models specific to HIV risk. AIDS Care. 2011;23(6):1-8.

38. Schneider J, Kaplan SH, Greenfield S, Li W, Wilson IB. Better physician-patient relationships are associated with higher reported adherence to antiretroviral therapy in patients with HIV infection. J Gen Intern Med. 2004;19:1096-103.

39. Kessler RC, Andrews G, Colpe LJ, et al. Short screening scales to monitor population prevalences and trends in non-specific psychological distress. Psychol Med. 2002;32:959-76.

40. Kessler RC, Barker PR, Colpe LJ, et al. Screening for serious mental illness in the general population. Arch Gen Psychiatry. 2003;60:184-9.

41. Chesney MA, Ickovics J, Chambers D, et al. Self-reported adherence to antiretroviral medications among participants in HIV clinical trials: the AACTG adherence instruments. AIDS Care. 2000;12:255-66.

42. Horne R, Weinman J, Hankins M. The beliefs about medicines questionnaire: the development and evaluation of a new method for assessing the cognitive representation of medication. Psychol Health. 1999;14:1-24.
43. Kalichman SC, Simbayi LC. HIV testing attitudes, AIDS stigma, and voluntary HIV counselling and testing in a black township in Cape Town, South Africa. Sex Transm Infect. 2003;79:442-7.

44. Remien RH, Hirky AE, Johnson MO, Weinhardt LS, Whittier D, Le GM. Adherence to medication treatment: a qualitative study of facilitators and barriers among a diverse sample of HIV+ men and women in four US cities. AIDS Behav. 2003;7:61-72.

45. Wagner G, Kanouse DE, Koegel P, Sullivan G. Correlates of HIV antiretroviral adherence in persons with serious mental illness. AIDS Care. 2004;16:501-6.

46. Pearson CR, Zhang F, Fredriksen-Goldsen K, et al. Barriers associated with self-reported adherence to antiretroviral therapy in Beijing, China. Poster presented at: 3rd annual international conference on HIV treatment adherence. March, 2008; Jersey City, NJ.

47. Barrera MA. A method for assessing social support networks in community survey research. Connections. 1980;3:8-13.

48. Arnsten JH, Li X, Mizuno Y, et al. Factors associated with antiretroviral therapy adherence and medication errors among HIV-infected injection drug users. JAIDS J Acquir Immune Defic Syndr. 2007;46:S64-71.

49. Fife BL, Wright ER. The dimensionality of stigma: a comparison of its impact on the self of persons with HIV/AIDS and cancer. J Health Soc Behav. 2000;41(1):50-67.

50. Simoni JM, Pearson CR, Pantalone DW, Marks G, Crepaz N. Efficacy of interventions in improving highly active antiretroviral therapy adherence and HIV-1 RNA viral load. A meta-analytic review of randomized controlled trials. J Acquir Immune Defic Syndr. 2006;43(Suppl 1):S23-35.

51. Moreno R, Mayer RE, Spires HA, Lester JC. The case for social agency in computer-based teaching: do students learn more deeply when they interact with animated pedagogical agents? Cogn Instr. 2001;19:177-213.

52. Wong IY, Lawrence NV, Struthers H, McIntyre J, Friedland GH. Development and assessment of an innovative culturally sensitive educational videotape to improve adherence to highly active antiretroviral therapy in Soweto, South Africa. J Acquir Immune Defic Syndr. 2006;43:S142-8. 